\title{
Perbaikan Kualitas Buah Jambu Biji (Psidium guajava L.) Kultivar Kristal dengan Berbagai Warna dan Bahan Pemberongsong
}

\author{
Improvement Fruit Quality of Guava (Psidium guajava L.) cv. Krystal By Different \\ Colors and Bagging Materials
}

\author{
Atika Romalasari ${ }^{1}$, Slamet Susanto ${ }^{2 *}$, Maya Melati ${ }^{2}$, dan Ahmad Junaedi ${ }^{2}$
}

Diterima 05 Oktober 2016/Disetujui 18 Oktober 2017

\begin{abstract}
Kristal guava is one of the popular guava cultivars nowadays. The guava has white flesh and not-perfectly-round shaped that resembles a crystal and seedless. However, during the growth period fruit undergoes several physical and chemical changes and susceptible to insect infestation and other damage, all of which can reduce their commercial value and thus cause significant yield and economic losses. The aim of this research was to evaluate the influence of different color and bagging materials on guava fruit development and quality. The research was conducted at farmer farm located in Cikarawang Dramaga, from November 2013 to April 2014. This research was arranged in a randomized block design with one factor, consisted of ten treatments and five replications. The treatments were red plastic, yellow plastic, green plastic, blue plastic, sponnet with red plastic, sponnet with yellow plastic, sponnet with green plastic, sponnet with blue plastic, sponnet with transparent plastic and unbagged. Fruit quality assesment was conducted in Postharvest Laboratory of Agronomy and Horticulture Department, Bogor Agricultural University and Center for Tropical Horticultural Studies. The result showed that bagging improved fruit size, external quality and accelerated fruit maturity. Sponnet with red plastic bagging resulted in the biggest fruit at harvest. Sponnet with yellow or with red plastic baggings were able to maintain fruit peel smoothness up to $85 \%$. Sponnet and plastic bagging resulted in better external quality than bagging with plastic only. Bagging did not show any effect on internal fruit quality.
\end{abstract}

Keywords: colored bag, guava cv. Kristal, soluble solids content, sponnet, titratable acidity

\begin{abstract}
ABSTRAK
Jambu 'Kristal' merupakan salah satu kultivar jambu biji yang sedang populer saat ini. Jambu Kristal memiliki daging buah berwarna putih, berbentuk bulat tidak beraturan serta berbiji sedikit. Selama pertumbuhan dan perkembangan buah mengalami berbagai perubahan fisik dan kimia dan rentan terhadap serangan hama, yang secara keseluruhan dapat mengurangi nilai komersial sehingga menyebabkan kehilangan yang signifikan dari segi hasil panen dan kerugian ekonomi. Tujuan dari penelitian ini adalah untuk menjelaskan pengaruh warna dan bahan pemberongsong terhadap perbaikan kualitas buah jambu 'Kristal'. Penelitian dilaksanakan pada November 2013 sampai April 2014, di kebun petani yang berlokasi di Cikarawang, Dramaga, Bogor. Penelitian menggunakan Rancangan Acak Kelompok dengan satu faktor yaitu pemberongsongan buah, dengan sepuluh taraf dan lima ulangan. Perlakuan pemberonsongan menggunakan plastik merah, plastik kuning, plastik hijau, plastik biru, sponnet dan plastik merah, sponnet dan plastik kuning, sponnet dan plastik hijau, sponnet dan plastik biru, sponnet dan plastik bening serta tanpa pemberongsong. Pengujian kualitas buah dilakukan di Laboratorium Pascapanen Departemen Agronomi dan Hortikultura, Fakultas Pertanian, Institut Pertanian Bogor dan Laboratorium Pusat Kajian Hortikultura Tropika (PKHT) IPB. Hasil penelitian menunjukkan bahwa pemberongsongan memperbaiki pertumbuhan, kualitas eksternal dan mempercepat pematangan buah. Pemberongsongan sponnet dan plastik merah menghasilkan buah
\end{abstract}

${ }^{1}$ Program Studi Agronomi dan Hortikultura, Sekolah Pascasarjana, Institut Pertanian Bogor

${ }^{2}$ Departemen Agronomi dan Hortikultura, Fakultas Pertanian, Institut Pertanian Bogor

Jl. Meranti, Kampus IPB Darmaga, Bogor 16680, Indonesia.

Email: slmtsanto@gmail.com (*penulis korespondensi) 
dengan ukuran terbesar pada saat panen. Pemberongsongan menggunakan sponnet dengan plastik kuning atau merah mampu menjaga kemulusan buah hingga 85\%. Pemberongsongan sponnet dan plastik menghasilkan kualitas eksternal yang cenderung lebih baik dibandingkan pemberongsongan hanya dengan plastik. Pembrongsongan tidak berpengaruh nyata terhadap kualitas internal buah.

Kata kunci: asam tertitrasi total, jambu 'Kristal', sponet, padatan terlarut total, pemberongsong berwarna

\section{PENDAHULUAN}

Jambu biji adalah salah satu buah nusantara unggulan yang berpotensi untuk bersaing di pasar global dan merupakan buah yang memiliki nilai gizi tinggi. Jambu 'Kristal' merupakan kultivar jambu biji yang telah resmi dilepas oleh Kementerian Pertanian berdasarkan SK Mentan No.540/Kpts/SR.120/9/2007 (Balitbu, 2007). Jambu 'Kristal' masuk ke Indonesia melalui Misi Teknik Taiwan (Taiwan Technical Mission in Indonesia) pada tahun 1998. Jambu biji tersebut disebut Kristal karena warna daging buahnya putih agak bening dengan bentuk buah agak berlekuklekuk bulat tidak sempurna menyerupai bentuk Kristal. Konsumen menyukai jambu 'Kristal' karena bertekstur renyah, memiliki cita rasa manis, dan berbiji lebih sedikit atau bahkan tidak berbiji sehingga porsi buah yang dapat dikonsumsi lebih banyak (Ditbenih, 2007).

Permintaan konsumen terhadap kualitas buah termasuk jambu terus meningkat seiring peningkatan pendapatan masyarakat. Rata-rata total peningkatan permintaan buah jambu 'Kristal' di Bogor sampai tahun 2013 mencapai 108.98\% (Sabrina, 2014). Namun demikian, kurang mulusnya penampilan buah jambu 'Kristal' merupakan masalah yang belum dapat sepenuhnya diatasi pekebun buah. Hal ini tercermin dari masih rendahnya persentase kemulusan buah yang dihasilkan petani. Pratidina (2013) melaporkan buah petani yang dijual ke ADC IPB-ICDF Taiwan dengan grade $\mathrm{B}+, \mathrm{B}$ dan $\mathrm{C}$ mencapai $69 \%$ atau yang masuk grade $\mathrm{A}$ (dengan kemulusan tinggi) hanya 31\% dari total jumlah panen selama tahun 2012.

Buah dengan nilai komersial tinggi umumnya juga dihasilkan oleh petani yang menerapkan phytosanitary dalam kegiatan budidaya, misalnya dengan pembungkusan buah di pohon yang biasa dikenal dengan istilah pemberongsongan (Blick et al., 2011). Pemberongsongan adalah teknik perlindungan secara fisik pada buah-buahan, yang tidak hanya memperbaiki kualitas visual dengan memperbaiki warna kulit dan mengurangi terjadinya pecah buah tetapi juga mengubah lingkungan mikro untuk perkembangan buah sehingga memberikan pengaruh pada kualitas internal buah, seperti yang dilaporkan pada apel (Fan dan Mattheis, 1998). Hingga saat ini penelitian mengenai perbaikan kualitas jambu 'Kristal' dengan metode pemberongsongan buah di Indonesia masih sedikit. Tujuan penelitian ini ialah untuk menjelaskan pengaruh warna dan bahan pemberongsong terhadap perbaikan kualitas buah jambu Kristal.

\section{BAHAN DAN METODE}

Penelitian dilaksanakan pada November 2013 sampai April 2014 di Kebun Jambu Kristal Cikarawang, Dramaga, Bogor. Analisis kualitas buah dilakukan di Laboratorium Pascapanen Departemen Agronomi dan Hortikultura, Fakultas Pertanian Institut Pertanian Bogor dan Laboratorium Pusat Kajian Hortikultura Tropika (PKHT) IPB.

Bahan yang digunakan ialah tanaman jambu Kristal produktif yang telah berumur empat tahun dan telah berbuah. Ukuran buah yang digunakan adalah buah dengan diameter $3.1 \pm 0.2 \mathrm{~cm}$ yang telah berkembang selama 4 MSA (Minggu Setelah Antesis). Pemberongsongan menggunakan lima warna plastik (merah, kuning, hijau, biru, dan bening) berbahan HDPE (High Density Polyethylene) dengan ukuran $27 \mathrm{~cm} \times 13.5 \mathrm{~cm}$ serta sponnet yang digunakan sebagai bahan pemberongsong.

Rancangan yang digunakan adalah Rancangan Acak Kelompok (RAK) dengan satu faktor yaitu pemberongsongan dengan 10 taraf yaitu plastik merah, plastik kuning, plastik hijau, plastik biru, sponnet dan plastik merah, sponnet dan plastik kuning, sponnet dan plastik hijau, sponnet dan plastik biru, sponnet dan plastik bening serta tanpa pemberongsong. Setiap perlakuan masing- 
masing diulang sebanyak 5 kali sehingga terdapat 50 satuan percobaan. Buah dipanen pada 13 minggu setelah anthesis (MSA) atau 9 minggu setelah pembrongsongan (MSP).

Pengamatan yang dilakukan meliputi kualitas eksternal dan internal buah. Perkembangan ukuran diameter melintang buah diukur setiap satu minggu sekali dengan menggunakan jangka sorong digital. Bobot buah diukur dengan menggunakan timbangan analitik segera setelah pemanenan. Kelunakan buah diukur dengan alat penetrometer elektrik dan dilakukan pada bagian pangkal, tengah, dan ujung buah, kemudian hasilnya merupakan rata-rata dari pengukuran tersebut. Tingkat kemulusan kulit buah diukur dengan membagi pengamatan buah menjadi delapan bagian secara proporsional, kemudian dihitung persentase kemulusan buah secara total. Warna kulit buah diukur menggunakan chromameter Konica Minolta CR 10 pada tiga sampel titik dengan metode CIELAB (McGuire, 1992) yang terdiri dari komponen nilai $\mathrm{L}^{*}$ (kecerahan), nilai derajat hue $\left(h^{\circ}\right)=\tan ^{-1}$ $\left(\mathrm{b} * / \mathrm{a}^{*}\right)$ dan chroma $\left(\mathrm{C}^{*}\right)=\left(\mathrm{a}^{* 2}+\mathrm{b}^{* 2}\right)^{1 / 2}$. Kandungan padatan terlarut total (PTT), asam tertitrasi total (ATT), dan Vitamin C ditentukan dengan menggunakan prosedur standar sesuai dengan AOAC (1995). Padatan terlarut total diukur melalui pembacaan langsung jus buah pada lensa refraktometer dan dinyatakan sebagai ${ }^{\circ}$ Brix. Asam tertitrasi total diukur melalui titrasi dengan $0.1 \mathrm{~N}$ $\mathrm{NaOH}$, dan dinyatakan sebagai persen. Vitamin $\mathrm{C}$ diukur melalui titrasi Iodium, dan dinyatakan dalam $(\mathrm{mg} / 100 \mathrm{~g})$. Data yang diperoleh diuji menggunakan uji $\mathrm{F}$ pada taraf nyata $\alpha=0.05$. Jika hasil uji $F$ menunjukkan bahwa perlakuan memberikan pengaruh secara signifikan, dilakukan uji lanjut jarak berganda Duncan Multiple Range Test (DMRT).

\section{HASIL DAN PEMBAHASAN}

\section{Kondisi Lingkungan Mikro dalam Pemberongsong Buah}

Perlakuan pembrongsongan mengakibatkan perbedaan suhu dan kelembaban relatif dalam pembrongsong. Ada indikasi pemberongsongan meningkatkan suhu dan menurunkan kelembaban relatif dalam pembrongsong. Pemberongsongan sponnet dan plastik meningkatkan suhu yang lebih tinggi dan kelembaban relatif yang lebih rendah dibandingkan pemberongsong plastik. Pemberongsongan sponnet dan plastik merah dan sponnet dan plastik biru menghasilkan suhu relatif lebih tinggi dibandingkan perlakuan lainnya (Tabel 1).

Warna dan bahan pemberongsong yang berbeda mempengaruhi penyerapan transmisi cahaya yang diteruskan ke dalam buah. Perbedaan warna pemberongsong menghasilkan kualitas cahaya dan panjang gelombang yang berbeda yang mempengaruhi pertumbuhan dan perkembangan buah peach (Zhang et al., 2015). Pemberongsongan sponnet dan plastik menghasilkan suhu yang lebih tinggi dibandingkan pemberongsong hanya plastik. Penggunaan sponnet sebagai bahan pemberongsong diduga membantu menjaga suhu yang dihasilkan dari penyerapan transmisi cahaya agar tidak mudah keluar pemberongsong. Pemberongsongan sponnet dan plastik merah menghasilkan suhu tertinggi karena warna merah merupakan warna dengan panjang gelombang yang tinggi sehingga mampu meneruskan transmisi cahaya yang tinggi.

Tabel 1. Kondisi lingkungan mikro dalam pemberongsong buah

\begin{tabular}{lcc}
\hline \multicolumn{1}{c}{ Perlakuan } & Suhu $\left({ }^{\circ} \mathrm{C}\right)$ & Kelembaban $(\%)$ \\
\hline Plastik Merah & 31.4 & 59 \\
Plastik Kuning & 30.4 & 60 \\
Plastik Hijau & 30.1 & 63 \\
Plastik Biru & 30.6 & 60 \\
Sponnet dan Plastik Merah & 32.6 & 59 \\
Sponnet dan Plastik Kuning & 30.8 & 60 \\
Sponnet dan Plastik Hijau & 30.7 & 58 \\
Sponnet dan Plastik Biru & 31.8 & 54 \\
Sponnet dan Plastik Bening & 31.1 & 58 \\
Tanpa Pemberongsong & 29.8 & 63 \\
\hline
\end{tabular}


Adanya peningkatan transmisi cahaya dari warna pemberongsong akan diikuti oleh peningkatan suhu yang dihasilkan. Yang et al. (2009) menyatakan bahwa jenis pemberongsong dengan transmisi cahaya yang tinggi menghasilkan iklim mikro yang mampu meningkatkan laju perkembangan buah, ukuran dan bobot buah. Di sisi lain Zhou et al. (2012) melaporkan bahwa kelembaban yang tinggi di dalam pemberongsong dapat menurunkan kekuatan sink dan laju transpirasi buah sehingga aliran asimilat ke dalam buah mengalami penurunan.

\section{Kualitas Eksternal Jambu Kristal}

Pemberongsongan buah nyata meningkatkan diameter melintang buah. Diameter melintang yang terbesar pada akhir percobaan diperoleh dari pemberongsongan dengan sponnet dan plastik merah (Tabel 2). Peningkatan diameter melintang buah akibat pemberongsongan diduga terkait dengan peningkatan suhu akibat pemberongsongan. Pada buah manga Lechaudel dan Joas (2007) melaporkan bahwa adanya peningkatan suhu akan meningkatkan kekuatan sink, seperti translokasi asimilat dan laju perkembangan buah.

Pemberongsongan berpengaruh sangat nyata terhadap bobot buah dan kecerahan warna buah serta nyata terhadap kemulusan, kelunakan dan nilai chroma buah, namun tidak nyata terhadap derajat hue warna buah (Tabel 3).

Pemberongsongan sponnet dan plastik menghasilkan ukuran buah yang lebih besar dibandingkan pemberongsong plastik saja. Bobot buah saat panen terbesar diperoleh dari perlakuan sponnet dengan plastik merah dan sponnet dengan plastik biru. Suhu pemberongsongan sponnet dan plastik merah dan sponnet dan plastik biru yang lebih tinggi dibandingkan suhu pembrongsongan perlakuan lainnya, menggambarkan kekuatan sink yang lebih besar yang memungkinkan penambahan ukuran buah yang lebih besar saat panen. Hasil ini sejalan dengan hasil penelitian Noorbaiti $e t$ al. (2013) pada jambu biji dan Kalsum (2015) pada jeruk pamelo. Penggunaan sponnet sebagai bahan pemberongsong diduga membantu menjaga suhu yang dihasilkan dari penyerapan transmisi cahaya agar tidak mudah ke luar pemberongsong.

Tabel 2. Perkembangan diameter melintang jambu kristal selama pemberongsongan di pohon sampai saat panen

\begin{tabular}{|c|c|c|c|c|c|c|c|c|c|c|}
\hline \multirow{2}{*}{ Perlakuan } & \multicolumn{10}{|c|}{ Minggu Setelah Pemberongsongan (MSP) (mm) } \\
\hline & 0 & 1 & 2 & 3 & 4 & 5 & 6 & 7 & 8 & $\begin{array}{c}9 \\
\text { (panen) }\end{array}$ \\
\hline Plastik Merah & 33.15 & 36.91 & 41.80 & 48.63 & 57.29 & $64.34 \mathrm{ab}$ & $72.02 \mathrm{a}$ & $78.04 \mathrm{ab}$ & $79.81 \mathrm{bc}$ & $88.34 \mathrm{bc}$ \\
\hline Plastik Kuning & 31.12 & 33.89 & 36.92 & 43.11 & 49.57 & $57.57 \mathrm{bc}$ & $66.72 \mathrm{ab}$ & $73.68 \mathrm{bc}$ & $81.18 \mathrm{abc}$ & $86.09 \mathrm{c}$ \\
\hline Plastik Hijau & 32.37 & 35.73 & 39.18 & 45.37 & 52.38 & $60.99 \mathrm{ab}$ & $68.93 \mathrm{a}$ & $76.61 \mathrm{ab}$ & $82.87 \mathrm{abc}$ & $85.93 \mathrm{c}$ \\
\hline Plastik Biru & 32.47 & 35.64 & 38.43 & 43.22 & 51.54 & $62.24 \mathrm{ab}$ & $71.45 \mathrm{a}$ & $75.78 \mathrm{ab}$ & $83.28 \mathrm{abc}$ & $87.58 \mathrm{c}$ \\
\hline $\begin{array}{l}\text { Sponnet dan Plastik } \\
\text { Merah }\end{array}$ & 33.02 & 36.59 & 41.51 & 48.03 & 56.44 & $62.72 \mathrm{ab}$ & $70.65 \mathrm{a}$ & $80.62 \mathrm{a}$ & $87.16 \mathrm{a}$ & $92.30 \mathrm{a}$ \\
\hline $\begin{array}{l}\text { Sponnet dan Plastik } \\
\text { Kuning }\end{array}$ & 30.53 & 36.02 & 40.34 & 45.89 & 51.91 & $60.81 \mathrm{ab}$ & $68.99 a$ & $75.96 \mathrm{ab}$ & $82.83 \mathrm{abc}$ & $88.33 \mathrm{bc}$ \\
\hline $\begin{array}{l}\text { Sponnet dan Plastik } \\
\text { Hijau }\end{array}$ & 29.75 & 35.22 & 41.07 & 45.43 & 53.66 & $61.48 \mathrm{ab}$ & $71.07 \mathrm{a}$ & $77.18 \mathrm{ab}$ & $83.93 \mathrm{ab}$ & $86.28 \mathrm{c}$ \\
\hline $\begin{array}{l}\text { Sponnet dan Plastik } \\
\text { Biru }\end{array}$ & 31.30 & 34.32 & 39.05 & 43.94 & 52.69 & $61.95 \mathrm{ab}$ & $69.14 \mathrm{a}$ & $75.86 \mathrm{ab}$ & $83.22 \mathrm{abc}$ & $92.00 \mathrm{a}$ \\
\hline $\begin{array}{l}\text { Sponnet dan Plastik } \\
\text { Bening }\end{array}$ & 31.03 & 36.73 & 40.72 & 50.07 & 57.87 & $66.73 \mathrm{a}$ & $73.74 \mathrm{a}$ & $79.31 \mathrm{ab}$ & $84.70 \mathrm{ab}$ & $90.30 \mathrm{ab}$ \\
\hline $\begin{array}{l}\text { Tanpa } \\
\text { Pemberongsong }\end{array}$ & 31.97 & 36.20 & 37.76 & 39.56 & 45.70 & $52.42 \mathrm{c}$ & $60.61 \mathrm{~b}$ & $69.96 \mathrm{c}$ & $77.33 \mathrm{c}$ & $82.91 \mathrm{~d}$ \\
\hline
\end{tabular}

Keterangan: Angka-angka pada kolom yang sama yang diikuti oleh huruf yang sama tidak berbeda nyata pada taraf uji 5\% (uji jarak berganda Duncan). **: sangat nyata. *: nyata. tn: tidak nyata. 
Tabel 3. Pengaruh pemberongsongan terhadap kualitas eksternal buah saat panen

\begin{tabular}{|c|c|c|c|c|c|c|}
\hline \multirow[b]{2}{*}{ Perlakuan } & \multirow[b]{2}{*}{ Bobot (g) } & \multirow{2}{*}{$\begin{array}{c}\text { Kemulusan } \\
(\%)\end{array}$} & \multirow{2}{*}{ 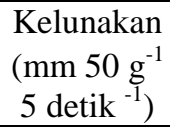 } & \multicolumn{3}{|c|}{ Warna } \\
\hline & & & & $\mathrm{L}^{*}$ & Hue $\left({ }^{0} h\right)$ & $\mathrm{C}^{*}$ \\
\hline Plastik Merah & $274.90 \mathrm{bc}$ & $63.3 \mathrm{bc}$ & $15.92 \mathrm{ab}$ & $52.73 \mathrm{a}$ & 94.40 & $31.40 \mathrm{a}$ \\
\hline Plastik Kuning & $266.30 \mathrm{c}$ & $73.7 \mathrm{ab}$ & $16.68 \mathrm{ab}$ & $54.66 \mathrm{a}$ & 97.18 & $31.57 \mathrm{a}$ \\
\hline Plastik Hijau & $255.60 \mathrm{bc}$ & $71.8 \mathrm{ab}$ & $12.35 \mathrm{bc}$ & $52.82 \mathrm{a}$ & 96.43 & $31.15 \mathrm{a}$ \\
\hline Plastik Biru & $280.70 \mathrm{abc}$ & $62.1 \mathrm{bc}$ & $16.74 \mathrm{ab}$ & $54.29 \mathrm{a}$ & 97.47 & $31.81 \mathrm{a}$ \\
\hline Sponnet dan Plastik Merah & $316.40 \mathrm{a}$ & $85.0 \mathrm{a}$ & $16.26 \mathrm{ab}$ & $52.23 \mathrm{a}$ & 95.78 & $31.09 \mathrm{a}$ \\
\hline Sponnet dan Plastik Kuning & $270.87 \mathrm{bc}$ & $85.8 \mathrm{a}$ & $17.53 \mathrm{a}$ & $53.38 \mathrm{a}$ & 97.92 & $31.31 \mathrm{a}$ \\
\hline Sponnet dan Plastik Hijau & $261.54 \mathrm{bc}$ & $77.3 \mathrm{ab}$ & $17.19 \mathrm{ab}$ & $54.09 \mathrm{a}$ & 96.38 & $31.52 \mathrm{a}$ \\
\hline Sponnet dan Plastik Biru & $314.40 \mathrm{a}$ & $80.0 \mathrm{ab}$ & $17.07 \mathrm{ab}$ & $54.46 \mathrm{a}$ & 96.61 & $31.36 \mathrm{a}$ \\
\hline Sponnet dan Plastik Bening & $291.80 \mathrm{ab}$ & $75.0 \mathrm{ab}$ & $18.00 \mathrm{a}$ & $53.22 \mathrm{a}$ & 97.21 & $31.65 \mathrm{a}$ \\
\hline Tanpa Pemberongsong & $252.11 \mathrm{c}$ & $46.4 \mathrm{c}$ & $9.16 \mathrm{c}$ & $49.15 \mathrm{~b}$ & 97.55 & $29.26 \mathrm{~b}$ \\
\hline
\end{tabular}

Keterangan: Angka-angka pada kolom yang sama yang diikuti oleh huruf yang sama tidak berbeda nyata pada taraf uji 5\% (uji jarak berganda Duncan). **: sangat nyata. *: nyata. tn: tidak nyata. $\mathrm{L}=$ kecerahan $\mathrm{C}=$ chroma.

Buah dengan tingkat kemulusan terbesar diperoleh dari pemberongsongan sponnet dan plastik kuning sebesar $85.8 \%$ namun tidak berbeda nyata dengan pemberongsongan sponnet dan plastik merah yang mencapai $85.0 \%$. Buah tanpa pemberongsong merupakan buah dengan kondisi kemulusan terendah dan hanya menghasilkan $46.4 \%$ buah mulus. Pemberongsongan menggunakan plastik dan sponnet mampu menjaga kemulusan buah cenderung lebih baik dibandingkan pemberongsongan hanya dengan plastik. Bagian buah yang bersentuhan langsung dengan pemberongsong plastik dapat berkurang kemulusannya akibat terbakarnya kulit buah. Muchui et al. (2010) melaporkan bahwa terdapat bagian seperti terbakar pada ujung buah pisang yang diberongsong menggunakan plastik polietilena biru akibat suhu terlalu panas. Sponnet berfungsi melindungi buah dari sentuhan langsung dengan bahan plastik yang dapat meningkatkan resiko penurunan kemulusan buah berupa terbakarnya kulit buah akibat peningkatan suhu.

Kelunakan buah saat panen meningkat dengan perlakuan pemberongsongan. Pemberongsongan sponnet dan plastik seluruhnya menghasilkan buah yang cenderung lebih lunak dibandingkan dengan pemberongsongan hanya dengan plastik. Suhu yang lebih tinggi pada pemberongsongan sponnet dan plastik disamping mempercepat pertumbuhan buah yang menghasilkan buah dengan ukuran yang lebih besar, diduga juga mendorong proses pemasakan buah yang lebih cepat sehingga buah menjadi lebih lunak pada saat panen dibandingkan dengan buah tanpa pembrongsong. Menurut Jain et al. (2003) pada jambu biji penyusun dinding sel seperti selulosa, lignin dan pati menurun selama pemasakan buah.

Pemberongsongan buah berpengaruh sangat nyata pada kecerahan warna dan nyata pada nilai chroma buah. Seluruh perlakuan pemberongsongan menghasilkan nilai kecerahan kulit buah yang lebih baik dibandingkan buah tanpa pemberongsong. Moon et al. (2015) juga melaporkan bahwa kecerahan warna kulit jeruk mandarin 'Shiranuhi' meningkat dengan adanya pemberongsongan buah.

Berdasarkan kuadran warna (McGuire 1992) $0^{\circ}=$ merah-ungu, $90^{\circ}=$ kuning, $180^{\circ}=$ hijau, dan $270^{\circ}=$ biru semakin rendah nilai derajat hue menunjukkan bahwa buah berwarna semakin kuning dan nilai chroma menggambarkan intensitas warna atau kemurnian nilai dari derajat hue. Nilai derajat hue buah menggambarkan warna buah yang terlihat yaitu hijau kekuningan $\left(94.40^{\circ}\right.$ $97.92^{\circ}$ ). Pada jambu biji selama pemasakan buah, kandungan klorofil buah menurun dan karotenoid buah meningkat yang mengakibatkan perubahan warna buah dari hijau menjadi kuning (Jain et al., 2003). Rendahnya nilai kecerahan buah (L) dan chroma pada perlakuan tanpa pemberongsong menggambarkan tampilan jambu kristal yang berwarna lebih gelap dan kusam. 
Tabel 4. Pengaruh pemberongsongan terhadap kualitas internal buah saat panen

\begin{tabular}{lcccc}
\hline \multicolumn{1}{c}{ Perlakuan } & $\begin{array}{c}\text { PTT } \\
\left({ }^{\circ} \text { Brix }\right)\end{array}$ & $\begin{array}{c}\text { ATT } \\
(\%)\end{array}$ & $\begin{array}{c}\text { Rasio } \\
\text { PTT:ATT }\end{array}$ & $\begin{array}{c}\text { Vitamin C } \\
(\mathrm{mg} / 100 \mathrm{~g})\end{array}$ \\
\hline Plastik Merah & $7.76 \mathrm{a}$ & $0.35 \mathrm{a}$ & $22.27 \mathrm{a}$ & $130.67 \mathrm{a}$ \\
Plastik Kuning & $7.32 \mathrm{a}$ & $0.36 \mathrm{a}$ & $20.33 \mathrm{a}$ & $131.84 \mathrm{a}$ \\
Plastik Hijau & $7.15 \mathrm{a}$ & $0.40 \mathrm{a}$ & $17.88 \mathrm{a}$ & $124.20 \mathrm{a}$ \\
Plastik Biru & $7.36 \mathrm{a}$ & $0.36 \mathrm{a}$ & $20.44 \mathrm{a}$ & $133.30 \mathrm{a}$ \\
Sponnet dan plastik merah & $7.48 \mathrm{a}$ & $0.38 \mathrm{a}$ & $19.68 \mathrm{a}$ & $131.33 \mathrm{a}$ \\
Sponnet dan plastik kuning & $7.42 \mathrm{a}$ & $0.38 \mathrm{a}$ & $19.53 \mathrm{a}$ & $139.82 \mathrm{a}$ \\
Sponnet dan plastik hijau & $7.41 \mathrm{a}$ & $0.37 \mathrm{a}$ & $20.03 \mathrm{a}$ & $130.85 \mathrm{a}$ \\
Sponnet dan plastik biru & $7.63 \mathrm{a}$ & $0.38 \mathrm{a}$ & $20.08 \mathrm{a}$ & $133.26 \mathrm{a}$ \\
Sponnet dan plastik bening & $7.71 \mathrm{a}$ & $0.36 \mathrm{a}$ & $21.42 \mathrm{a}$ & $146.18 \mathrm{a}$ \\
Tanpa pemberongsong & $6.80 \mathrm{a}$ & $0.51 \mathrm{a}$ & $13.33 \mathrm{a}$ & $121.30 \mathrm{a}$ \\
\hline Keng
\end{tabular}

Keterangan: Angka-angka pada kolom yang sama yang diikuti oleh huruf yang sama tidak berbeda nyata pada taraf uji 5\% (uji jarak berganda Duncan). **: sangat nyata. *: nyata. tn: tidak nyata. PTT: padatan terlarut total. ATT: asam tertitrasi total.

\section{Kualitas Internal Jambu Kristal}

Pemberongsongan buah cenderung meningkatkan kandungan PTT dan Rasio PTT/ATT serta menurunkan kandungan ATT buah. Buah tanpa pemberongsong cenderung memiliki kandungan PTT lebih rendah, ATT yang lebih tinggi, Rasio PTT/ATT yang rendah dan Vitamin $\mathrm{C}$ yang rendah. Hal ini diduga buah tanpa pembrongsong dengan kondisi suhu buah yang lebih rendah mengalami proses perkembangan dan kematangan buah yang lebih lambat dibandingkan dengan buah dengan pembrongsongan. Menurut Pantastico et al. (1986) hasil analisis kadar ATT buah menunjukkan pola hiperbolik, yaitu peningkatan selama pematangan buah dan mencapai maksimum pada tahap akhir pematangan buah kemudian menurun pada saat memasuki fase pemasakan buah. Pada papaya yang tidak dibrongsong, perbedaan kandungan vitamin $\mathrm{C}$ atau kandungan kimia buah dipengaruhi umur panen yang berbeda (Taris et al., 2015) Hasil percobaan menunjukkan kandungan vitamin $\mathrm{C}$ jambu kristal tidak dipengaruhi oleh pemberongsongan buah. Hal ini sejalan dengan Noorbaiti et al. (2013) yang melaporkan bahwa kandungan Vitamin $\mathrm{C}$ jambu biji tidak dipengaruhi oleh warna pemberongsong.

\section{KESIMPULAN}

Pemberongsongan mampu mempercepat perkembangan, tingkat kematangan dan kemulusan buah. Pemberongsongan menggunakan plastik merah dan sponnet menghasilkan ukuran buah terbesar. Pemberongsongan sponnet dan plastik seluruhnya menghasilkan buah dengan kualitas eksternal yang cenderung lebih baik dibandingkan pemberongsongan hanya dengan plastik. Perlakuan pemberongsongan tidak meningkatkan kualitas internal buah.

\section{DAFTAR PUSTAKA}

AOAC. 1995. Official Method of Analysis of Association Official Agriculture Chemist. Washington DC.

[Balitbu] Balai Penelitian Tanaman Buah Tropika. 2007. Budidaya Jambu Biji. http://hortikultura.litbang.pertanian.go.i d/ [14 April 2015].

Blick, A.P., S.R. Roberto, M.V.E. Grossmann, F. Yamashita. 2011. Efficacy of some biodegradable films as preharvest covering material for guava. Sci. Hort. 130:341-343.

[Ditbenih] Direktorat Perbenihan Hortikultura. 2007. Deskripsi Jambu Biji Varietas Kristal.

http://varitas.net/dbvarietas/deskripsi/31 36.pdf. [30 Juli 2015].

Fan, X., J.P. Mattheis. 1998. Bagging 'Fuji' apples during fruit development affects colour development and storage quality. HortScience. 33: 1235-1238. 
Jain, N., K. Dhawan, S. Maholtra, R. Singh. 2003. Biochemistry of fruit ripening of guava (Psidium guajava $\mathrm{L}$.): compositional and enzymatic changes. Plant Foods for Human Nutr. 58: 309-315.

Kalsum, U. 2015. Perbaikan kualitas jeruk pamelo (Citrus maxima (Burm).Merr). melalui pengaturan nisbah jumlah daun: buah dan pemberongsongan buah. [Tesis]. Sekolah Pascasarjana Institut Pertanian Bogor. 38 hal.

Lechaudel, M., J. Joas. 2007. An overview of preharvest factors influencing mango fruit growth, quality and postharvest behavior. Braz. J. Plant Physiol. 19(4): 287-298.

McGuire, GR. 1992. Reporting of objective color measurements. HortScience. 27(12): 1254-1255.

Moon, D.G.,S.W. Ko, S.G. Han, C.H. Kim, C.K. Lim, J.H. Joa. 2015. Effect of bagging on 'Shiranuhi' mandarin fruit quality during growth and storage. Intl. J. Eng. and Appl. Sci. 2(7): 2394-3661.

Muchui, M.N., F.M. Mathooko, C.K. Njoroge,E.M. Kahangi, C.A. Onyango, E.M. Kimani. 2010. Effect of perforated blue polyethylene bunch covers on selected postharvest quality parameters of tissuecultured bananas (Musa spp.) cv. Williams in Central Kenya. J. Stored Products and Postharvest Res. 1(3): 2941.

Noorbaiti, I., S. Trisnowati, S. Mitrowihardjo. 2013. Pengaruh warna plastik dan umur pembrongsongan terhadap mutu buah jambu biji (Psidium guajava L.). Vegetalika. 2(1): 44-53.
Pantastico EB. 1986. Fisiologi Pasca Panen Penanganan dan Pemanfaatan BuahBuahan dan Sayur-sayuran Tropika dan Subtropika. Kamariyani, penerjemah; Tjitrosoepomo G, editor. Yogyakarta (ID): Gadjah Mada University Press.

Pratidina, R. 2013. Analisis pengelolaan dan pengendalian mutu jambu kristal dengan menggunakan metode six sigma di ADC IPB-ICDF Taiwan, Bogor. [Skripsi]. Departemen Manajemen Fakultas Ekonomi dan Manajemen Institut Pertanian Bogor. 31 hal.

Sabrina, P.A. 2014. Perbandingan analisis kelayakan usaha jambu kristal (Psidium guajava L.) petani mandiri dengan petani binaan ICDF Kabupaten Bogor. [Skripsi]. Departemen Agribisnis Fakultas Ekonomi dan Manajemen Institut Pertanian Bogor. 142 hal.

Taris, M.L., W.D. Widodo, K. Suketi. 2015. Kriteria kemasakan buah pepaya (Carica papaya (L.) IPB Callina dari beberapa umur panen. J. Hort. Indonesia. 6(3): 172-176.

Yang WH, Zhu XC, Bu JH, Hu GB, Wang HC, Huang XM. 2009. Effects of bagging on fruit development and quality in cross-winter off-season longan. Scientia Hort. 120: 194-200.

Zhang, B., R.J. Ma, Z.X. Cia, C.H. Zhang. Z.M. Yan. 2015. Effect of preharvest microenvironment inside bags on peach fruit quality. Plant Physiol. 51(2): 233240.

Zhou, J., G. Zhong, Z. Lin, H.L. Xu. 2012. The effects of bagging on fresh fruit quality of Canarium album. J. Food, Agric. \& Env. 10(1): 505-508. 